\title{
Physical and Aerodynamic Properties of Lavender in relation to Harvest Mechanisation
}

\author{
Christos I. Dimitriadis, ${ }^{1,2}$ James L. Brighton, ${ }^{1}$ Mike J. O'Dogherty, \\ Maria I. Kokkora, ${ }^{1,3}$ and Anastasios I. Darras ${ }^{4}$ \\ ${ }^{1}$ Environmental Science and Technology Department, School of Applied Science, Cranfield University, \\ Cranfield, Bedfordshire MK43 OAL, UK \\ ${ }^{2}$ Department of Agricultural Technology, Alexandrio Technological Educational Institute of Thessaloniki, \\ 57400 Thessaloniki, Greece \\ ${ }^{3}$ Technological Research Center of Thessalia, Technological Educational Institute of Larissa, 41110 Larissa, Greece \\ ${ }^{4}$ Department of Agricultural Technology, Technological Educational Institute of Peloponnese, Antikalamos, \\ 24100 Kalamata, Greece
}

Correspondence should be addressed to Christos I. Dimitriadis; dimchristos@hotmail.com

Received 23 April 2014; Accepted 18 September 2014; Published 7 October 2014

Academic Editor: Othmane Merah

Copyright (C) 2014 Christos I. Dimitriadis et al. This is an open access article distributed under the Creative Commons Attribution License, which permits unrestricted use, distribution, and reproduction in any medium, provided the original work is properly cited.

\begin{abstract}
A laboratory study evaluated the physical and aerodynamic properties of lavender cultivars in relation to the design of an improved lavender harvester that allows removal of flowers from the stem using the stripping method. The identification of the flower head adhesion, stem breakage, and aerodynamic drag forces were conducted using an Instron 1122 instrument. Measurements on five lavender cultivars at harvest moisture content showed that the overall mean flower detachment force from the stem was $11.2 \mathrm{~N}$, the mean stem tensile strength was $36.7 \mathrm{~N}$, and the calculated mean ultimate tensile stress of the stem was $17.3 \mathrm{MPa}$. The aerodynamic measurements showed that the drag force is related with the flower surface area. Increasing the surface area of the flower head by $93 \%$ of the "Hidcote" cultivar produced an increase in drag force of between $24.8 \%$ and $50.6 \%$ for airflow rates of 24 and $65 \mathrm{~m} \mathrm{~s}^{-1}$, respectively. The terminal velocities of the flower heads of the cultivar ranged between 4.5 and $5.9 \mathrm{~m} \mathrm{~s}^{-1}$, which results in a mean drag coefficient of 0.44 . The values of drag coefficients were compatible with well-established values for the appropriate Reynolds numbers.
\end{abstract}

\section{Introduction}

Design engineers working with plant material need to know their properties and structures when subjected to cutting, bending, tensile, and compressive forces in order to understand the behaviour of the material in conjunction with the machine involved. A designer should therefore be conversant with the physical and mechanical properties of the investigated plant. Apparently there is no published research on factors affecting physical and mechanical properties of lavender plant and therefore this is a novel work falling in this area.

Aromatic plants and their essential oils are a source of natural medicines and plant protection agents. They contain secondary metabolic products, which have biological activity, such as antibacterial, antifungal, or antioxidant properties [1]. Lavender is one of those aromatic plants and has been used widely for its cosmetic, cleansing, and healing qualities. It is a plant that is distributed worldwide and cultivated mainly for its oil and flowers (fresh and dried).

The most common genus for this purpose is Lavandula, which belongs to the family Lamiaceae. This genus is divided into six sections, namely, Lavandula, Stoechas, Dentata, Pterostoechas, Chaetostachys, and Subnuda [2-4], and is characterized by square stems, lipped flowers, and paired leaves. The flowers are placed in whorls towards the end of the stem introducing an inflorescence. Studies have shown that $97.5 \%$ of the lavender oil is within the flower and that the oil quality distilled from the flower is much higher than that of the stem [5]. Therefore, for the most refined oil, 
it is required to separate flower from stem [6], an operation which is traditionally performed by hand.

Conventional harvesting methods of lavender, such as hand harvesting and mechanical harvesting, are expensive due to high labour and operating costs. Several lavender harvester machines exist, but all remove both the stem and the flower. These methods increase the transportation and distillation costs and are undesirable for the production of high quality oil [6].

The stripping technique has not been applied to lavender, even though there would appear to be a clear advantage of this technique for the production of oil. The stripping technique was developed for the harvesting of cereals [7, 8]. A similar approach to that of the stripper concept used for cereals may be employed, but the physical characteristics of lavender are significantly different and unknown. Thus, it is necessary to determine the parameters that govern the detachment of the lavender flower heads in order to facilitate the design of a lavender harvester, which separates the flower from the stem based on the stripping technique.

In handling and processing of agricultural products, air is often used as a carrier or as a helper to transport a product. In this case, air flow occurs around the transported particles and involves the action of the exerted forces by the fluid on these particles. In free fall, an object will attain a constant terminal velocity at which the net gravitational accelerating force equals the resisting upward drag force [9]. If an air stream is applied to a particle that is higher than its terminal velocity, then this particle would move in the direction of the air stream. It is necessary, therefore, to have knowledge of some physical properties which affect the aerodynamic behaviour of the lavender as a transported particle, such as its drag coefficient and the terminal velocity.

This study aimed to identify the detachment force required to separate the flower from the stem, along with the aerodynamic properties of the plant to enable the design process of a novel lavender harvester to be conducted efficiently. The particular objectives of the current study were to evaluate the forces required to detach the flowers from the stems and the ultimate tensile stress (UTS) and to investigate the drag forces exerted by the flower when subjected to an air stream and the flowers' terminal velocities when falling freely in air.

\section{Materials and Methods}

2.1. Plant Material. Within the family Labiatae, genus Lavandula is the most common commercially applied and grown for oil production. Two species are commonly used for their oil in the UK, namely, Lavandula angustifolia and Lavandula $x$ intermedia, which were both selected for the trial. Their primary characteristics were as follows: plant height $0.60-$ $1.00 \mathrm{~m}$, peduncle length $0.10-0.30 \mathrm{~m}$, spike length $0.07-$ $0.16 \mathrm{~m}$, and peduncle alignment $40^{\circ}-90^{\circ}$ [10].

"English Lavender," Lavandula angustifolia, is the most widely cultivated species and its cultivars are the hardiest and most fragrant of all lavender [4]. Lavandula angustifolia cultivars are very fragrant and can be used for fresh or dried flowers, fragrant products, and ornamental, hedging, or container purposes. It is one of the sweeter members of this group and is suitable for culinary purposes and oil production. Lavandula $x$ intermedia or "lavandins" cultivars are sterile hybrids between Lavandula angustifolia and Lavandula latifolia. Despite the lower oil quality (AFNOR standards), the higher yield [11] in comparison to other lavender species made the "lavandins" very popular for oil production.

Three representative lavender cultivars, namely, "Folgate," "Hidcote," and "Maillette," from Lavandula angustifolia species and two cultivars, namely, "Alba" and "Grosso," from Lavandula $x$ intermedia species were chosen. These cultivars were chosen due to their widespread use in the UK and their availability.

Eight different crop samples were taken and were categorised as follows by cultivar: "Hidcote" (a) and "Hidcote" (c) were both harvested from Cranfield University, Silsoe (Bedfordshire, UK), and were in their 2nd and 3rd year of growth, respectively; "Hidcote" (b) and "Alba" were harvested from Zwetsloot \& Sons Ltd. greenhouses (Sandy, Bedfordshire, UK) and both were in their 3rd year of growth. "Grosso" (b) was harvested from a commercially cultivated area at Carshalton (London, UK) and was in its 3rd year of growth. "Maillette," "Folgate," and "Grosso" (a) were harvested from a commercially cultivated area at Cadwell farm at Hitchin (Bedfordshire, UK).

All samples were harvested at the commercial harvest stage for oil production with more than $50 \%$ of the inflorescence in bloom [12]. Moisture content $(\mathrm{m} / \mathrm{c})$ was measured on a wet basis (w.b.) using ASAE Standard 358.2 [13] and was a mean of $58.5 \%$ for "Hidcote" (a), $72.0 \%$ for "Hidcote" (b), $69.0 \%$ for "Hidcote" (c), 69.3\% for "Alba," 67.3\% for "Maillette," 58.0\% for "Folgate," 65.0\% for "Grosso" (a), and $67.4 \%$ for "Grosso" (b).

2.2. Flower Detachment Force Identification. The aim of this experiment was to quantify the detachment force required to separate the flower from the stem and the ultimate tensile strength (UTS) of the stem. Two tests were conducted. The first test was to quantify the measurement forces for the lavender flower at a typical harvest moisture content and the second test investigated the influence of the moisture content at these measurement forces.

2.2.1. Quantification in Measurement Forces at Harvest Moisture Content. The first test aimed to identify the detachment force required to separate the flower from the stem, the stem breaking force, and the UTS of the stem at a typical harvest moisture content. This occurs when $50 \%$ of the flowers are open in each head flower [12]. To determine the force required to detach the flower from the stem, each sample was placed within a fixture attached to an Instron 1122 test machine, as shown in Figure 1. All plants were cut with $100 \mathrm{~mm}$ length of peduncle and were placed upside down in the instrument (Figure 1(a)). The stem was fitted into the end of the load cell after being passed through a fixed hole of $3 \mathrm{~mm}$ diameter in a metal plate to the bottom of the instrument. The flower part was below the hole. As the cross-head section 


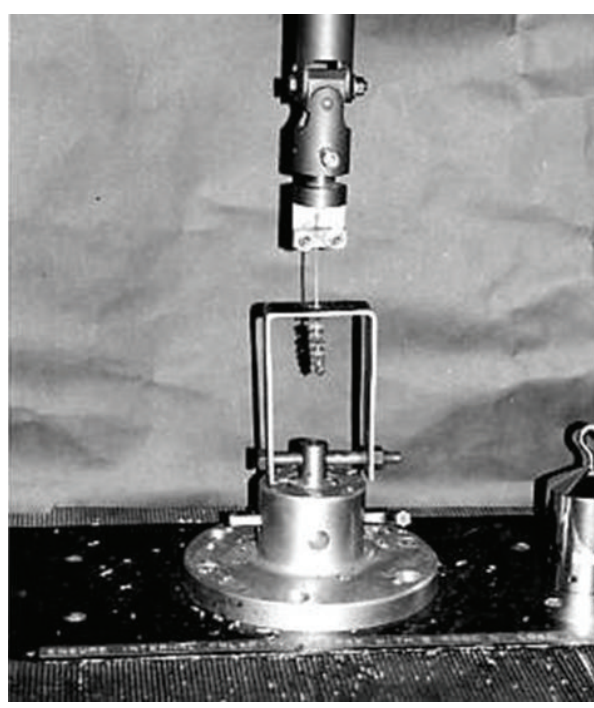

(a)

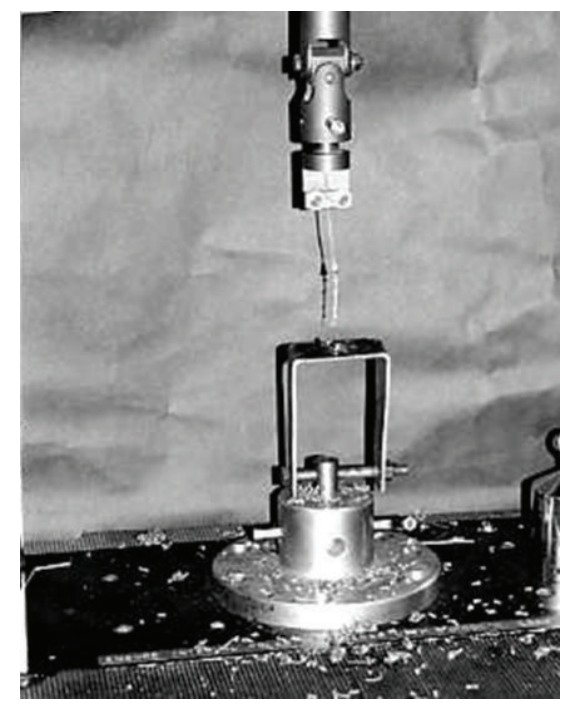

(b)

FIGURE 1: Flower detachment force measurement using an Instron 1122 test machine. Sample placement (a) before detachment and (b) after detachment.

moved upwards the stripping procedure was conducted. The test was stopped when the stem was completely clear of the metal plate (Figure 1(b)).

Two treatments were examined for all cultivars: one treatment consisting of five replications for the flower detachment force identification and one treatment consisting of five replications for the stem breaking force measurement. When one experiment was complete the same procedure was followed for the next flower. The force was recorded using the recording part of the Instron 1122 instrument which was equipped with a chart drive unit. The cross-head velocity and the chart speed of the Instron 1122 were selected at $50 \mathrm{~mm} \mathrm{~min}^{-1}$. Greater detachment velocities were used but the results were inconsistent and exhibited a high degree of variation due to the collection of plant material around the hole within the metal fixture. Therefore $50 \mathrm{~mm} \mathrm{~min}^{-1}$ was chosen for all tests.

After the flower detachment experiments, the same stems consisting of a $50 \mathrm{~mm}$ long peduncle were used to measure the stem breaking force and calculate the UTS. The procedure was the same as that for the detachment experiment with the exception that both ends of the stem were attached to the Instron 1122 instrument as shown in Figure 2. Measurements of the stem tensile strength and the cross-sectional area of each sample were used to calculate the UTS of the stem for each cultivar. The UTS was calculated as the quotient of the tensile strength divided by the cross-sectional area $\left(\mathrm{N} \mathrm{mm}^{-2}\right)$.

All 8 crop samples were used for this experiment, namely, "Hidcote" (a), "Hidcote" (b), "Hidcote" (c), "Alba," "Maillette," "Folgate," "Grosso" (a), and "Grosso" (b). Thirty replicates for each crop sample were taken for both experiments. Moisture content was measured 3 times for every crop sample.

2.2.2. Effect of Plant Moisture Content. This test was conducted to allow for a comparison between the cultivars

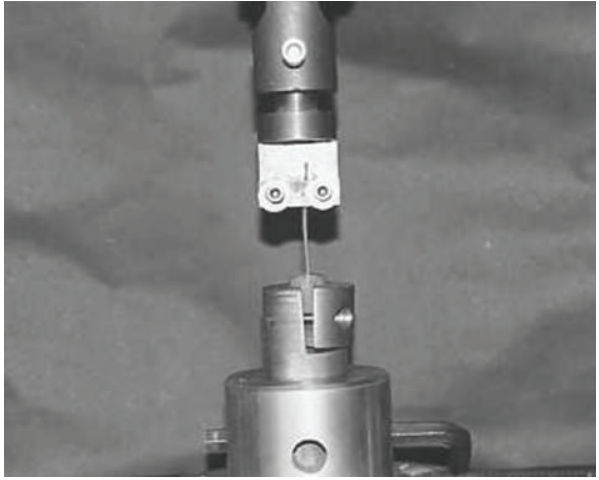

FIGURE 2: Measurement of stem tensile strength using an Instron 1122 test machine.

and also the adjustment of the results from the previous experiments to a single moisture content $(\mathrm{m} / \mathrm{c})$. The same method as that described in Section 2.2.1 was used to measure the detachment force and the stem breaking force. Crop samples were taken from "Hidcote" (c), "Maillette," "Folgate," "Grosso" (a), and "Grosso" (b) and tested across a range of moisture contents from $72 \%$ to $19 \%$ (wet basis (w.b.)). Each test was replicated five times and the samples were chosen randomly.

Between each set of measurements the sample was allowed to dry for 4 hours at room temperature. The decline in the $\mathrm{m} / \mathrm{c}$ was recorded by taking samples for each set of flowers which was tested. The recorded relative humidity during the test was $55 \%$ and the temperature $25^{\circ} \mathrm{C}$.

In order to compare the results between cultivars, data were used to normalize the measurement forces at the specific $\mathrm{m} / \mathrm{c}$ of $58 \%$ (w.b.), which constitutes the representative $\mathrm{m} / \mathrm{c}$ found among cultivars during the harvest period in the UK. 


\subsection{Flower Aerodynamic Properties Identification}

2.3.1. Flower Terminal Velocity. According to Mohsenin [14], it is difficult to find the terminal velocity of an irregular shape plant material, but using (1) below (adopted from Lapple [15]) and estimating the cylindrical area of the plant shapes, the terminal velocity can be estimated. Experiments, however, must be conducted to identify the terminal velocity for valid conclusions. Therefore both empirical and analytical approaches were used and the results were compared.

For the theoretical determination of terminal velocity $\left(V_{T}\right)$, an expression was adopted from that given by Lapple [15] and applied to the flower heads (see also Mohsenin [14]), as shown in (1)-(2) as follows:

$$
V_{T}^{2}=\frac{\left(\rho_{L} / \rho_{A}-1\right) d g}{2 C_{D}},
$$

from which

$$
C_{D}=\frac{\left(\rho_{L} / \rho_{A}-1\right) d g}{2 V_{T}^{2}},
$$

where $\rho_{L}$ is the density of the flower head $\left(\mathrm{kg} \mathrm{m}^{-3}\right), \rho_{A}$ is the density of air $\left(\mathrm{kg} \mathrm{m}^{-3}\right), d$ is the flower head diameter $(\mathrm{m}), g$ is the acceleration due to gravity $\left(\mathrm{m} \mathrm{s}^{-2}\right)$, and $C_{D}$ is the drag coefficient.

The method used to empirically determine the terminal velocity was based upon that used by Mueller et al. [16], in which the sample was attached to a force transducer. The end of a vacuum pump hose was placed above the flower head. A $32 \mathrm{~mm}$ diameter hose extension was lowered over the flower head, completely covering it (Figure 3 ). The transducer was set to read only when the flower of the sample was placed upon it, such that, with the sample in place with no air flow, the balance reads the mass of the flower.

Three air flow treatments were conducted at air flow rates of 24,45 , and $65 \mathrm{~m} \mathrm{~s}^{-1}$ and the resulting transducer readings were taken. An additional air flow measurement was taken when the transducer read zero. Each test was replicated 3 times. The crop sample used was "Hidcote."

2.3.2. Flower Aerodynamic Drag Resistance. Inflorescences (including the stem) of 34 to $64 \mathrm{~mm}$ long were used to determine the relationship between inflorescence length and aerodynamic drag. A vacuum pump was used to create the air stream for the purpose of the experiment. The plants were placed upside down in the end of the vacuum hose. Into the end of the plastic hose, a clear plastic tube of $32 \mathrm{~mm}$ diameter was fitted. This permitted a clear view through the tube to record any reaction of the flower. At one end of the stem, a small diameter nylon line was attached. The other end of the nylon was attached to the load cell to measure the force as shown in Figure 4.

The experiment was conducted at air speeds of 24,45 , and $65 \mathrm{~m} \mathrm{~s}^{-1}$. Lower air speeds were not considered because of precision limitations of the recording instrument. The air speed was measured using a vane anemometer. Fifteen treatments and three replications in each of the three different

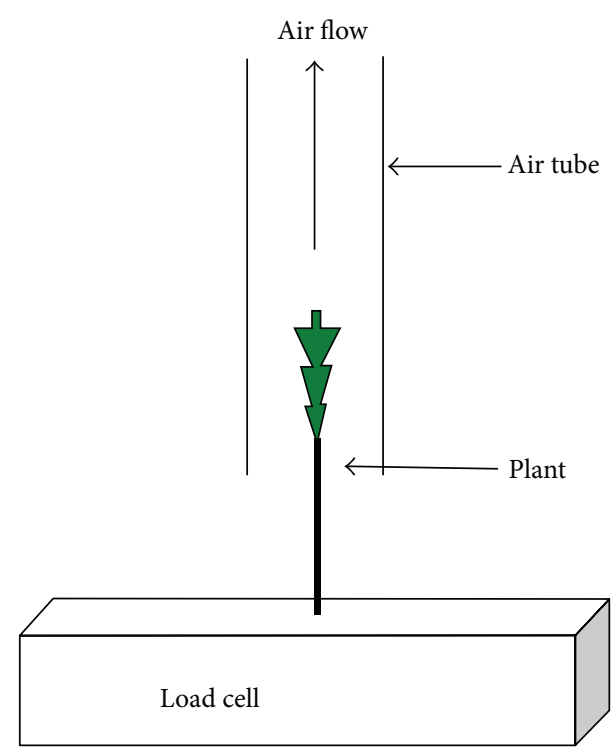

FIGURE 3: Schematic diagram illustrating the apparatus for measurement of flower terminal velocity.

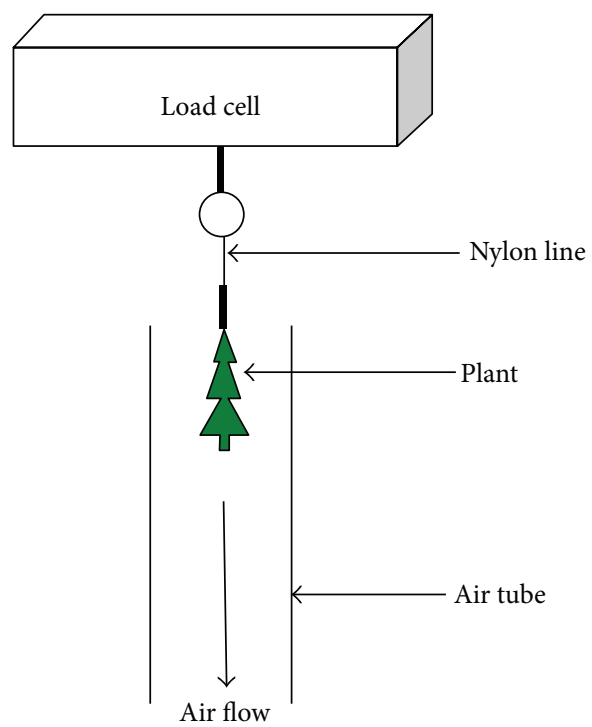

FIGURE 4: Schematic diagram illustrating the apparatus for measurement of flower aerodynamic drag resistance.

air speeds were examined. Before each flower was tested, measurements of length, diameter, and weight of the inflorescences were taken for each sample. The crop sample used was "Hidcote."

To define the geometry of each flower head a metric was devised to encompass the flower head in a cylinder, the surface area of which, excluding the top and bottom surfaces, was termed the "cylindrical surface area of the flower."

The measurements of the drag forces on the flowers were used to calculate an approximation of the drag coefficient of the flower heads using (3)-(4) as follows:

$$
F_{D}=\frac{1}{2} \rho v^{2} C_{D} A,
$$




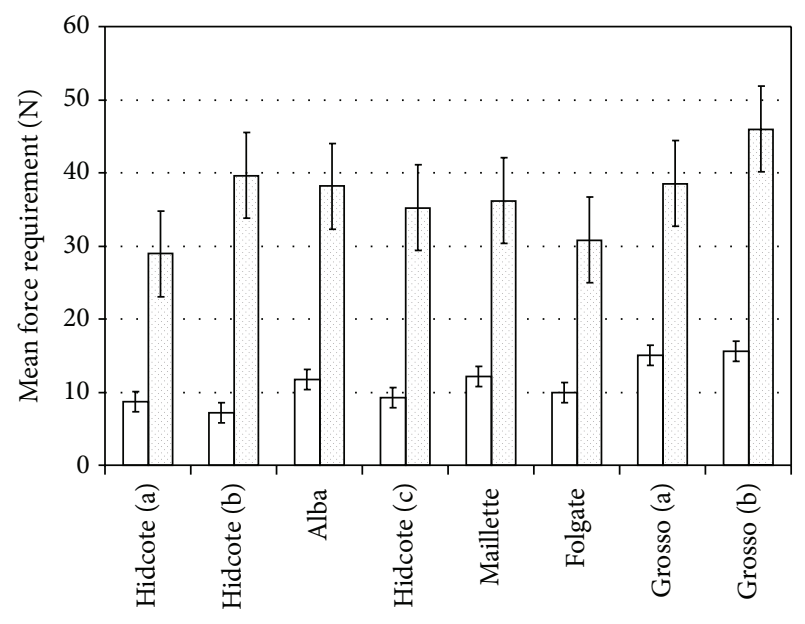

Lavender cultivar

- Flower detachment force

- Stem breaking force

FIGURE 5: Mean flower detachment force and stem tensile failure force for eight lavender crop samples showing overall mean of $95 \%$ confidence limits.

where $F_{D}$ is the drag force $(\mathrm{N}), \rho$ is the air density $\left(\mathrm{kg} \mathrm{m}^{-3}\right)$ $\left(\right.$ taken as $\left.1.2 \mathrm{~kg} \mathrm{~m}^{-3}\right), v$ is the air stream velocity $\left(\mathrm{m} \mathrm{s}^{-1}\right), C_{D}$ is the drag coefficient, and $A$ is cross-sectional area of the flower (as viewed from above) $\left(\mathrm{m}^{2}\right)$.

The drag coefficient is, therefore, given by

$$
C_{D}=\frac{2 F_{D}}{\rho v^{2} A} \text {. }
$$

\section{Results and Discussion}

3.1. Flower Detachment Force and Stem Tensile Strength Results at Harvest Moisture Content. For the 8 crop samples examined, the mean flower detachment force was $11.2 \mathrm{~N}$, ranging from $7.1 \mathrm{~N}$ for "Hidcote" (b) to $25.6 \mathrm{~N}$ for "Grosso" (b). The mean values are shown in Figure 5 together with the pooled least significant differences at the $95 \%$ level. The detachment forces for "Grosso" (a) and "Grosso" (b) were significantly greater than those for the other six crop samples, with mean values of $15.0 \mathrm{~N}$ and $15.6 \mathrm{~N}$, respectively. The smallest detachment forces were recorded for "Hidcote" (b), which had a mean value of $7.1 \mathrm{~N}$, which was significantly lower $(P<0.05)$ than "Maillette," "Folgate," "Grosso" (a), and "Grosso" (b) with the exception of the two crop samples of "Hidcote" (a) and "Hidcote" (c).

The stem tensile strength was found to vary over a range from $28.9 \mathrm{~N}$ for "Hidcote" (a) to $46.0 \mathrm{~N}$ for "Grosso" (b) (Figure 5). Overall, there were no significant differences between crop samples except for the "Hidcote" (a) and "Folgate" which had significantly smaller mean values than that recorded for "Grosso" (b).

The important finding from these measurements, which is shown clearly in Figure 5, is that the stem tensile strength, with a mean value of $36.7 \mathrm{~N}$, was significantly greater $(P<$ $0.05)$ than the flower detachment forces required, with a mean value of $11.2 \mathrm{~N}$, that is, by a factor of 3.3. Considering all replicates, the minimum stem tensile strength $(28.9 \mathrm{~N})$ was greater than the maximum flower detachment force $(25.6 \mathrm{~N})$. For all cultivars the average force required to break the stem was considerably greater (2.6 to 5.6 times) than the average force required to detach the flower from the stem in harvest conditions for oil production. This suggests that, in practice, the flower can be mechanically stripped from the stems without stem breakage.

3.2. Stem Ultimate Tensile Stress (UTS). The ultimate tensile stress for the 8 crop samples was measured at harvest moisture content (w.b.) (Figure 6). The magnitudes of the measured values ranged from 12.1 MPa for the "Hidcote" (a) sample to $23.1 \mathrm{MPa}$ for the "Folgate" sample with an overall mean value of 17.3 MPa.

The "Maillette" and "Folgate" crop samples had significantly greater ultimate tensile stress than the "Hidcote" (a) and "Grosso" (a) but were not significantly different $(P>$ $0.05)$ from the "Hidcote" (b), "Hidcote" (c), "Grosso," (b) and "Alba."

\subsection{Effect of Moisture Content on Flower Detachment Force} and Stem Tensile Strength. It was found that both flower detachment force and stem tensile strength showed significant linear decreases with increasing moisture content over a range from $19 \%$ to $72 \%$ (w.b.). The mean rate of linear decrease of flower detachment force was $0.082 \mathrm{~N}$ per $\% \mathrm{~m} / \mathrm{c}$, and for the stem tensile strength the mean decrease was $0.448 \mathrm{~N}$ per $\% \mathrm{~m} / \mathrm{c}$.

To compare the results for the different lavender cultivars on a similar basis it was decided to normalise the measured forces to the appropriate value at a moisture content of $58 \%$ (w.b.). The mean flower detachment and stem strength forces were plotted in Figure 7 together with the pooled least significant differences for the 5 crop samples, namely, "Grosso" (b), "Grosso" (a), "Hidcote" (b), "Folgate," and "Maillette."

The flower detachment forces were significantly greater for the "Grosso" (b) and "Grosso" (a) at $16.6 \mathrm{~N}$ and $16.5 \mathrm{~N}$, respectively. This result is in accord with that for the mean forces from all 8 crop samples at harvest moisture content for flower detachment.

The stem tensile strength was also the greatest for the "Grosso" (a) and "Grosso" (b) at $57.7 \mathrm{~N}$ and $46.9 \mathrm{~N}$, respectively. The measurements of the stem tensile strength were much greater than those for flower detachment with a force ratio of 3.2 for the overall mean stem breakage forces of $43.5 \mathrm{~N}$ and flower stripping forces of $13.4 \mathrm{~N}$, respectively. The finding to note is that the average force required to break the stem was found to be greater than the average force required to detach the flower from the stem and ranged from 2.8 to 3.8 times.

\subsection{Flower Aerodynamic Measurements}

3.4.1. Terminal Velocity. Three determinations of the terminal velocity of the flower heads were made which gave values of 4.5, 4.8, and $5.9 \mathrm{~m} \mathrm{~s}^{-1}$. Fifteen replicates of "Hidcote" crop 


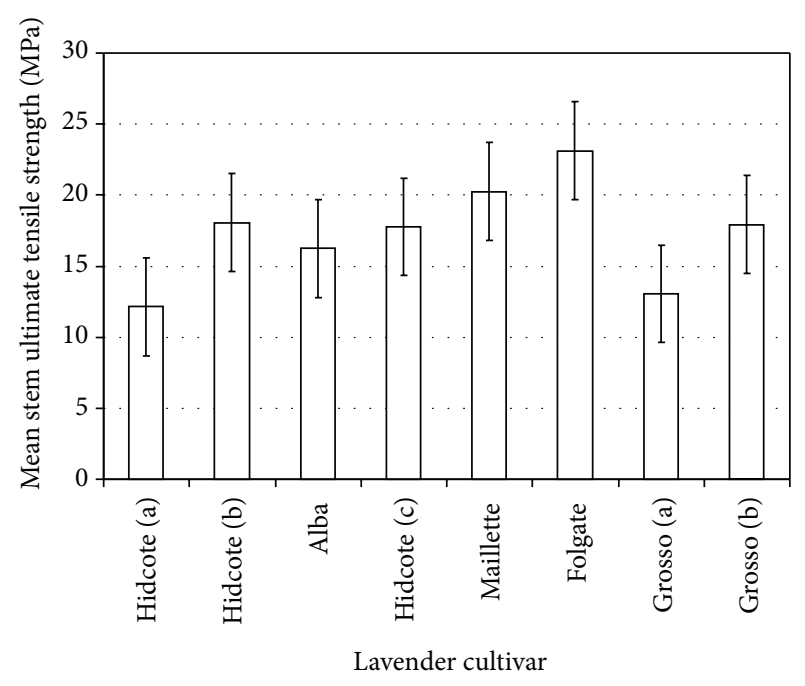

FIgURE 6: Mean stem ultimate tensile stress for the eight lavender crop samples showing overall mean of $95 \%$ confidence limits.

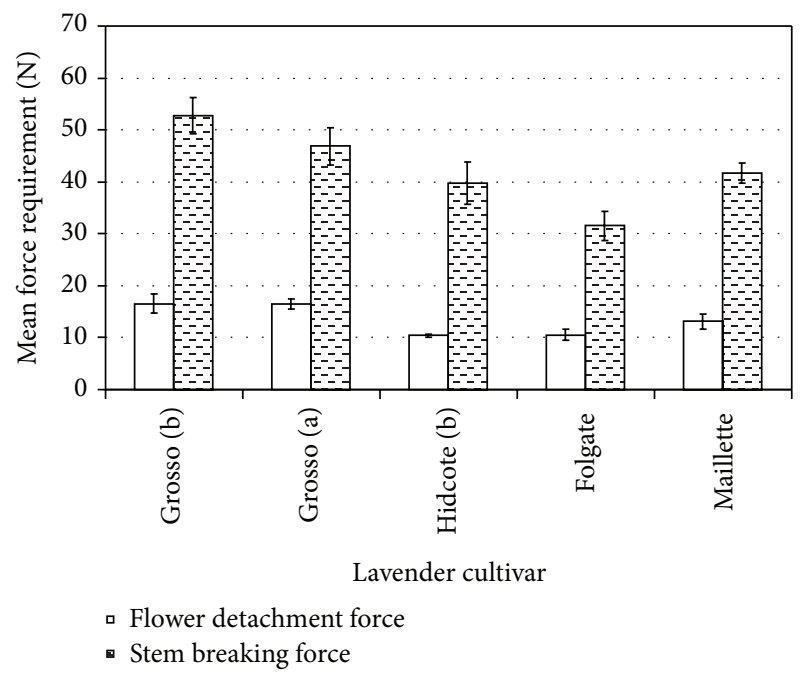

FIgURE 7: Mean flower detachment force and stem tensile failure force for five lavender cultivars normalized to a moisture content of $58 \%$ wet basis showing $95 \%$ confidence limits.

sample gave a mean flower head density of $212 \mathrm{~kg} \mathrm{~m}^{-3}$ and a mean diameter of $0.015 \mathrm{~m}$. If the $C_{D}$ is assumed to have a value of 0.5 , (1) results in a value of the terminal velocity of $5.08 \mathrm{~m} \mathrm{~s}^{-1}$, which is equal to the mean for the measured values. The observed data were collected from flower heads with diameters varying from 11 to $13 \mathrm{~mm}$ and if the densities are taken as equal to $212 \mathrm{~kg} \mathrm{~m}^{-3}$ then the mean value of $C_{D}$ which was calculated from (2) is equal to 0.44 .

It is of interest that at a velocity of $5 \mathrm{~m} \mathrm{~s}^{-1}$ the Reynold's number in air is equal to approximately 5000 , which is in the turbulent flow region. For the measurements of drag forces, the Reynold's numbers were in a range of approximately 24,000 to 65,000 for the velocity range of 24 to $65 \mathrm{~m} \mathrm{~s}^{-1}$, for which the drag coefficients ranged from 0.32 to 0.18 . These values are compatible with the greater value of drag coefficient observed at the terminal velocity of $5 \mathrm{~m} \mathrm{~s}^{-1}$, which is consistent with greater drag coefficients which have been found to occur at lower Reynold's numbers. Overall, the values estimated for the drag coefficients were of a magnitude consistent with those which have been experimentally found for discs, spheres, and cylinders over a wide range of Reynold's numbers $[17,18]$.

It is necessary to determine the terminal velocity of the lavender flower so that the machine could be designed with sufficient air flow to move the crop in the desired manner. The terminal velocity found from the tests exceeded in a small amount those found using Lapple's equation. Taking into account the two approaches a range of 4 to $6 \mathrm{~m} / \mathrm{s}$ as terminal velocity for the flower head can be used to determine the absolute lower limit of the air flow.

3.4.2. Flower Aerodynamic Drag Resistance. The effect of the "cylindrical surface area of the flower" on the measured drag force is shown in Figure 8 for air stream velocities of 24, 45 , and $65 \mathrm{~m} \mathrm{~s}^{-1}$ for a range of surface area from 1671 to $3217 \mathrm{~mm}^{2}$. There was an increase in drag force with increasing surface area of $50.6 \%, 25.8 \%$, and $24.8 \%$ over the range of areas examined for 24,45 , and $65 \mathrm{~m} \mathrm{~s}^{-1}$ air stream velocities, respectively. The linear correlation between drag coefficient and air stream velocity was close to a value of the coefficient of variation, $R^{2}=0.975$. The values of the coefficient of variation were relatively low, particularly at air stream velocities of $45 \mathrm{~m} \mathrm{~s}^{-1}$ and $65 \mathrm{~m} \mathrm{~s}^{-1}$, which reflected the magnitude of the variations in the measured drag forces.

The overall mean drag forces for all three air stream velocities were plotted in Figure 9 together with the mean $95 \%$ least significant difference values. There was an increase in the overall mean drag force by a factor of 4.0 from $0.019 \mathrm{~N}$ to $0.076 \mathrm{~N}$, over the air stream velocity range of 24 to $65 \mathrm{~m} \mathrm{~s}^{-1}$. There was a close linear correlation between mean drag force and air stream velocity with a coefficient of determination, $R^{2}=0.999$. The drag coefficient decreased by $44.1 \%$ from 0.32 to 0.18 over the air stream velocity range of 24 to $65 \mathrm{~m} \mathrm{~s}^{-1}$ (Figure 9). This effect may arise because as the air stream velocity increases the flower heads tend to be deflected towards the stem so as to present less aerodynamic resistance from a flattening effect and possibly to a reduction in the actual cross-sectional area.

\section{Conclusions}

The force required to detach the flower from the stem was less than that required to break the stem in all cases tested. The UTS for the upper stem of the lavender plant was found to range from $12.13 \mathrm{MPa}$ to $23.12 \mathrm{MPa}$. The mean detachment flower force ranged between 8.6 and $15.6 \mathrm{~N}$ depending upon the cultivars physical characteristics. The mean stem breaking force, for each of the cultivars tested, ranged between 28.9 and $46.0 \mathrm{~N}$. Therefore it can be predicted that, for these cultivars, the stripping method can always be applied. During the flower detachment force tests, a relationship between moisture content and measured forces was obtained. As the moisture content decreased the measured forces for flower 


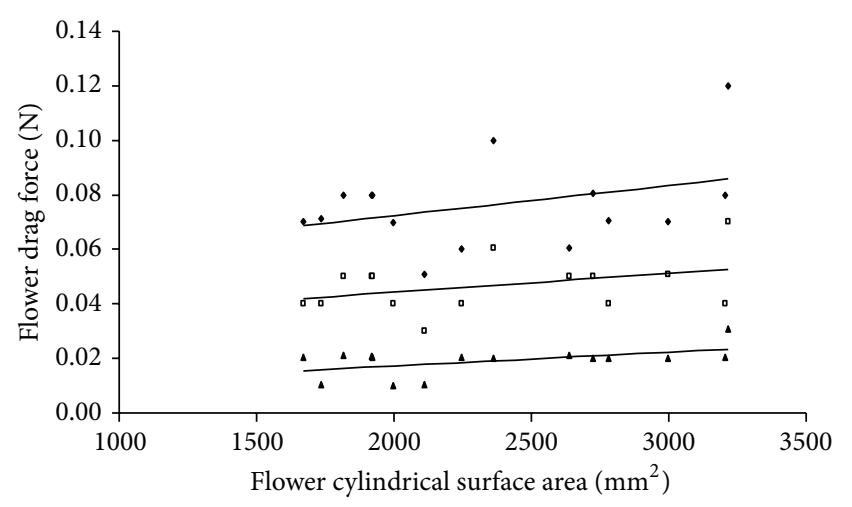

- Air stream velocity $24 \mathrm{~m} / \mathrm{s}$

- Air stream velocity $45 \mathrm{~m} / \mathrm{s}$

- Air stream velocity $65 \mathrm{~m} / \mathrm{s}$

FIGURE 8: Variation in flower drag force with "cylindrical surface area of the flower" for three mean air stream velocities (crop sample Hidcote).

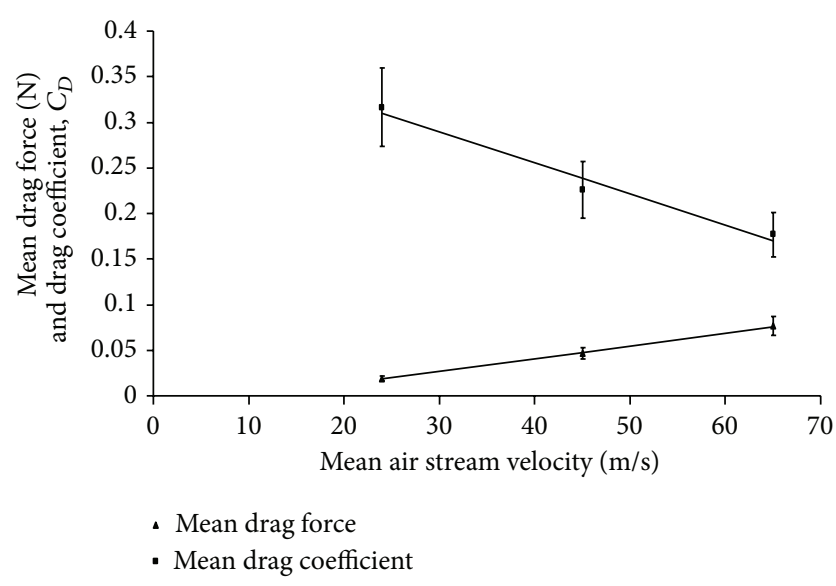

FIGURE 9: Variation in mean flower head drag force and drag coefficient with mean air stream velocity showing $95 \%$ confidence limits for mean values.

detachment and stem breakage increased. This relationship was used to allow a comparison between tested cultivars at different moisture contents, over the typical harvest moisture content range of 58 to $69 \%$ (w.b.). The force measurement data showed a specific pattern for each cultivar. In the future, this may prove to be useful for the identification of cultivars because the trends appeared to be different for each cultivar tested and to be a function of the flowering pattern.

The aerodynamic measurements showed that the drag force due to an air stream passing over the flower heads increased with the flower surface area. An increase in "cylindrical surface area of the flower" of $93 \%$ gave rise to an increase in drag force of $50.6 \%, 25.8 \%$, and $24.8 \%$ for air stream velocities of 24,45 , and $65 \mathrm{~m} \mathrm{~s}^{-1}$, respectively.

The overall mean drag force increased by a factor of 4 over the range of air stream velocity from 24 to $65 \mathrm{~m} \mathrm{~s}^{-1}$. The measured terminal velocities of the flower heads varied between 4.5 and $5.9 \mathrm{~m} \mathrm{~s}^{-1}$, the mean value of which is in good agreement with a theoretically predicted value. The values of the drag coefficients found for the flower heads were of a magnitude consistent with those expected for the range of Reynold's numbers appropriate to the experiments. This knowledge needs to be taken into consideration in the machinery designing process for adequate transportation of the detached flower to a container within the novel harvester to be achieved.

\section{Conflict of Interests}

The authors declare that there is no conflict of interests regarding the publication of this paper.

\section{Acknowledgments}

The first author is grateful to the Greek State Scholarships Foundation (IKY) for their financial support of this work. In addition, thanks are due to Alec Hunter and Doug Worley for their permission to conduct experiments in their lavender crops and to Bioregional Ltd. for their provision of materials and the test field area. Thanks are also due to a number of colleagues at the Engineering Group of the National Soil Resources Institute (Cranfield University, UK) for help and support during the work.

\section{References}

[1] N. G. Deans and K. P. Svoboda, Biological Activity of Plant Volatile Oils. Volatile Oil Crops: Their Biology, Biochemistry and Production, Longman, London, UK, 1993.

[2] D. A. Chaytor, "A taxonomic study of the genus Lavandula", Journal of the Linnean Society of London, Botany, vol. 51, no. 338, pp. 153-204, 1937.

[3] A. G. Miller, "The genus Lavandula in Arabia and Tropical NE Africa," Notes RBG Edinburge, vol. 42, no. 3, pp. 503-528, 1985.

[4] V. McNaughton, Lavender-The Grower's Guide, Garden Art Press, Woodbridge, Conn, USA, 2000.

[5] P. R. Venskutonis, A. Dapkevicius, and M. Baranauskiene, "Composition of the essential oil of Lavender (Lavandula angustifolia mill) from Lithuania," Journal of Essential oil Research, vol. 9, no. 1, pp. 107-110, 1997.

[6] M. Grieve, “A Modern Herbal," September 2001, http://www .botanical.com/botanical/mgmh/l/lavend13.html.

[7] W. E. Klinner, M. A. Neale, A. A. Geike, and N. R. Hobson, "Feasibility assessments of an in-situ grain and seed stripping mechanism," Divisional Note 1316, National Institute of Agricultural Research, pp. 11-19, 1986.

[8] N. R. Hobson, J. S. Price, C. R. Tuck, M. A. Neale, and O. D. Hale, Evaluation and Development of the Grain Stripping Header System-1986, Divisional Note 1443, AFRC Institute of Engineering Research, 1988.

[9] M. Hayden and J. Soule, "An investigation of some aerodynamic properties of lowbush blueberries," in Presented as Paper No 68847 at the Winter Meeting of the American Society of Agricultural Engineering, Chicago, Ill, USA, 1968.

[10] C. I. Dimitriadis, The design of an improved efficiency lavender harvester [Ph.D. thesis], Cranfield University at Silsoe, Bedford, UK, 2005. 
[11] Casabianca, AFNOR standards, http://www.therealessentials .com/.

[12] N. G. Porter, M. L. Shaw, and L. C. Hurndell, "Preliminary studies of lavender as an essential crop for New Zealand," New Zealand Journal of Agricultural Research, vol. 25, no. 3, pp. 389394, 1982.

[13] American Society of Agricultural and Biological Engineers, "Moisture measurement: Forages," Standard ASAE 358.2.

[14] N. N. Mohsenin, Physical Properties of Plant and Animal Materials, Gordon and Breach, 2nd edition, 1986.

[15] C. R. Lapple, Fluid and Particle Mechanics, University of Delaware, Newark, Del, USA, 1956.

[16] R. A. Mueller, D. B. Brooker, and J. J. Cassidy, "Aerodynamic properties of black walnuts: application in separating good from bad walnuts," in Proceedings of the Summer Meeting of the American Society of Agricultural Engineering, paper no. 66-338, Amherst, Mass, USA, 1966.

[17] J. C. Hunsaker and B. G. Rightmire, Engineering Applications of Fluid Mechanics, McGraw-Hill, New York, NY, USA, 1947.

[18] W. L. Badger and J. T. Banchero, Introduction to Chemical Engineering, McGraw-Hill, 1955. 


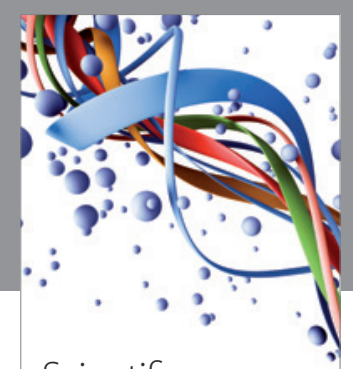

Scientifica
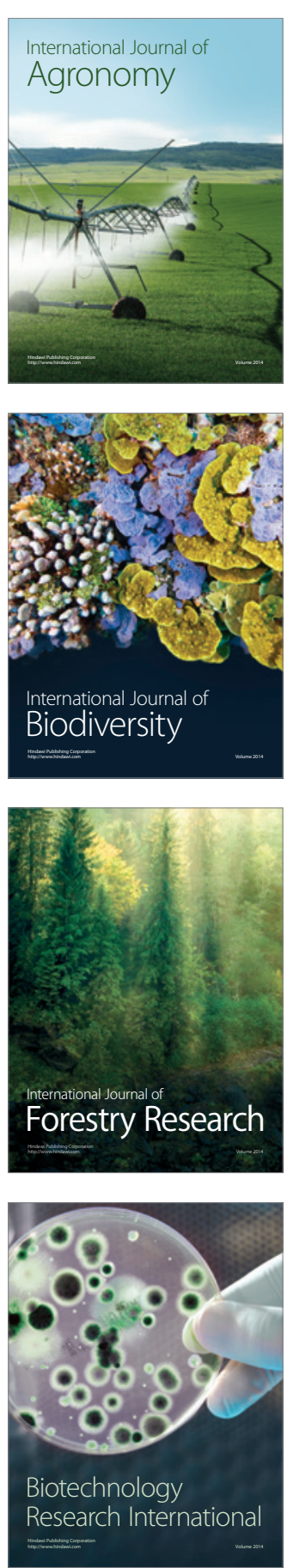
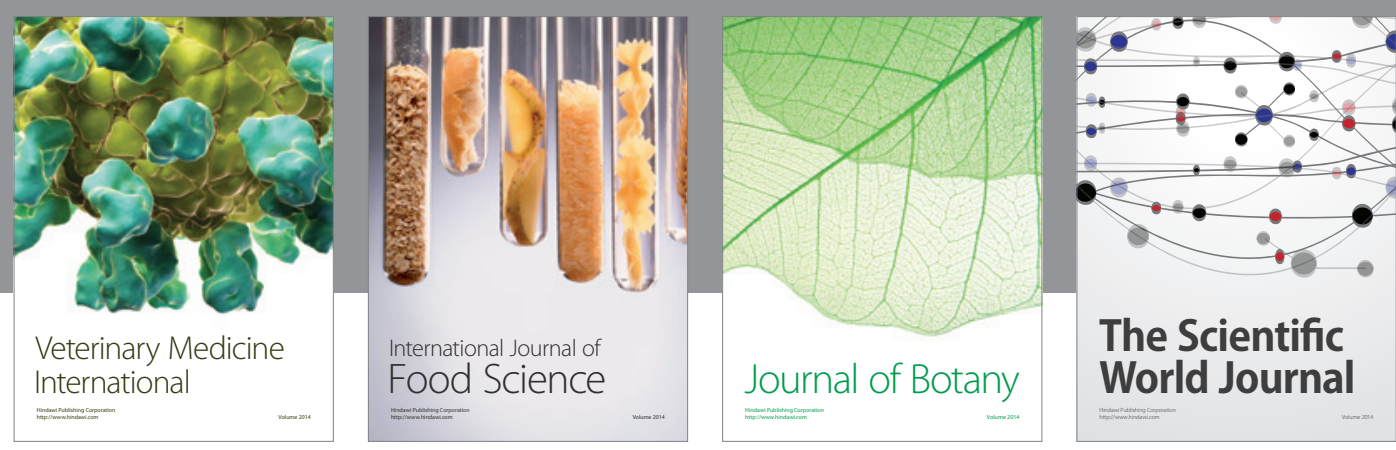

The Scientific World Journal
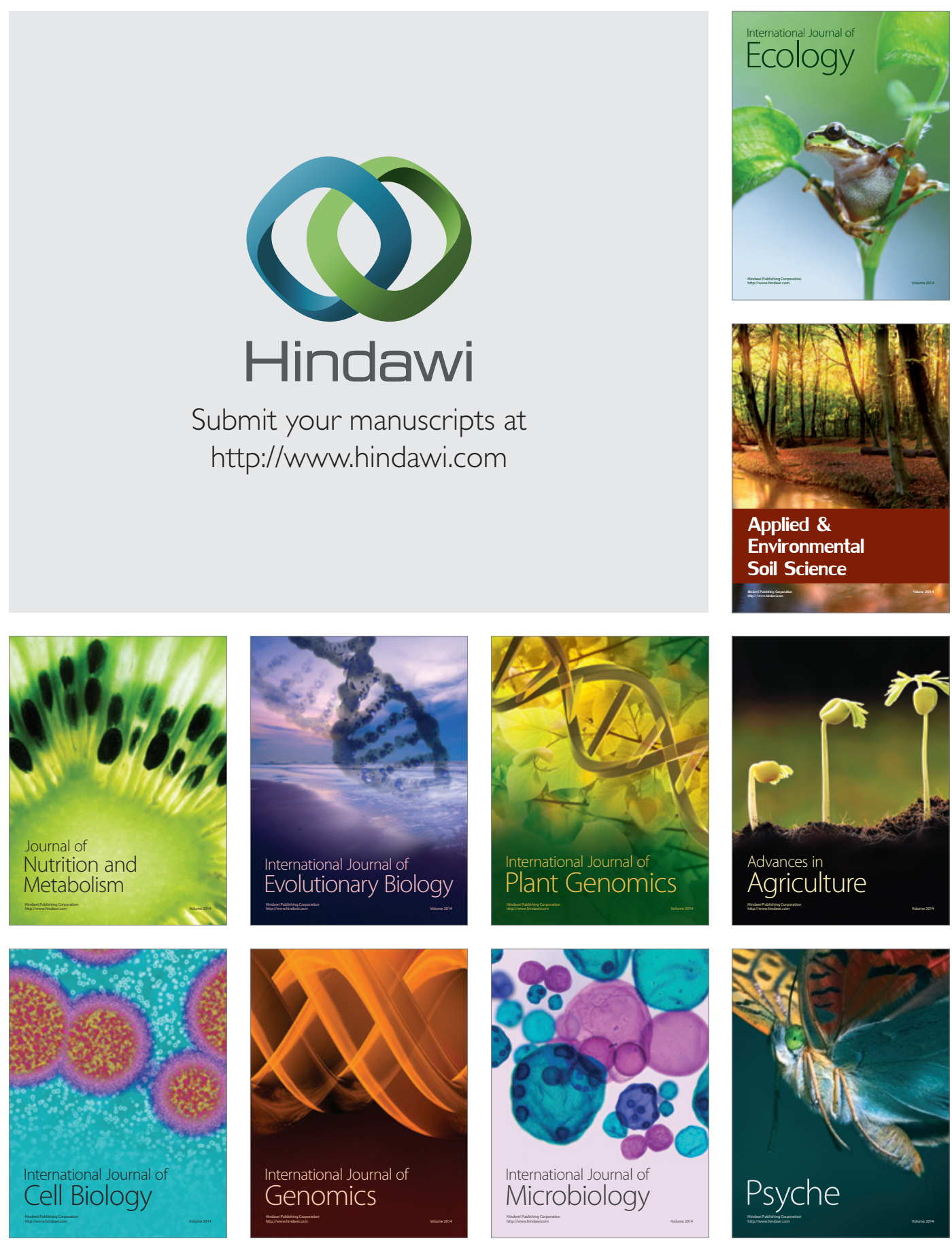